\title{
The evaluation of hydrodynamic balance at the Wkra River estuary
}

\author{
Piotr Siwicki, Janusz Urbański, Leszek Hejduk, Jacek Gładecki \\ Warsaw University of Life Sciences (SGGW), Nowoursynowska 166, 02-787 Warsaw, Poland, e-mail: piotr_siwicki@sggw.pl, \\ janusz_urbanski@sggw.pl, leszek_hejduk@sggw.pl, jacek_gladecki@sggw.pl
}

\begin{abstract}
The river bed stability analysis at the Wkra estuary reach is presented in this paper. When a flood appears, channel and river bed erosion can reach a significant size. During such a situation, flow and water velocity exceed critical values for particular bed sediment grain sizes. This causes the breakage of bed armouring, and then bed mass motion begins.

For the estimation of the sandy Wkra River bed the criteria of average velocity and bed armouring were applied with the use of ARMOUR software. The two Wkra River cross-sections at km 1+000 and km 3+200 distance were analysed. The calculation of the characteristics of bed sediment velocities was performed on the basis of, among other factors, probable river flow data, longitudinal slope, and grain size distribution of the bed. The results of the calculations were compared with average velocities in the analysed cross-sections.

The results indicate the there is a threat to the stability of the Wkra River bed, especially during long-lasting high water stages. The prognosis of river bed stability loss performed by use of ARMOUR software shows that the bed armour breakage will take place in both considered cross-sections at relatively low water stages (about $40 \mathrm{~cm}$ ), and mass motion of bed sediments in cross-section P-2 will occur at a flow of slightly lower than $Q_{50 \%}$, and in cross-section P-1 at flows greater then $Q_{0,3 \%}$.
\end{abstract}

Key words: river bed stability, armoring, bed load, Wkra River

Submitted 13 January 2016, revised 24 April 2016, accepted 28 July 2016

\section{Introduction}

The natural process of the formation of rivers and valleys is the result of a complex interaction of water flow and the movement of solid material caused by flow (Żelazo, Popek 2014).

Riverbeds, due to fluvial processes (erosion, sediment transport and accumulation) are transformed in both vertical and horizontal planes. Bed erosion contributes to the deepening and bank erosion leads to the widening and shifting of the river channel (Bajkiewicz-Grabowska, Mikulski 2007; Bednarczyk, Duszyński 2008). Increased bed erosion is the cause of the acceleration of erosion of rivers banks. The banks on the concave bends of the rivers are the most exposed to these processes, which is a reason for the meandering of a channel in a river valley. It involves the continuous process of concave banks collapsing and the accumulation of eroded material at convex banks (Przedwojski 1998). Fluvial processes depend on natural factors like discharge and its duration, grain size distribution of bed material, bank resistance to erosion processes and the geometry of the channel (Odgaard 1984; Przedwojski 1998; Bąk, Michalik 2010). The erosion processes and sediment transport increase with both the size of a flood and its duration because (Kaszowski, Kotarba
1970; Urbański, Hejduk 2014) velocities in the channel in such cases significantly exceeded critical particle movement values. According to Bartnik et al. (2007), the character of fluvial processes defines the intensity of sediment movement and transport capabilities of a water body. The intensity of sediment movement $(I)$ is the amount of material transported in a river during a particular flow condition for a specified time step. River transport capability $(Z)$ is a maximum potential value of the transport which can occur for a particular flow condition and material characteristic (like grain sizes, density). Depending on the relationship of these two parameters, the following processes can occur: sedimentation, when $I>Z$; erosion, when $I<Z$; hydrodynamic balance, when $I=Z$.

This methodology of fluvial processes analysis can be applied in cases when the results of sediment transport in various flow conditions are available. However, in many cases such detailed field surveys do not exist. In these cases, it is possible to apply simplified methods like the determination of a flow boundary condition when the particles of a river bed start to move (Popek 2004, 2010; Hämmerling et al. 2014a, b).

One of the basic problems in research on fluvial processes is the question of critical conditions for the initiation of the motion of bed load particles (Popek 2004, 2010; 
Hämmerling et al. 2014a, b). Critical conditions can be determined according to shear stress at a channel bottom or the water velocity close to a river bottom, average velocities in hydrometric verticals or average velocities in a whole cross-section of a channel. The parameter that determines the phenomenon of bed sediment motion is shear stress at a river bottom as a result of water movement. From a practical point of view, critical velocity is often used, because velocity is a measurable value, as opposed to shear stress (Popek 2004; Hämmerling et al. 2014a, b).

For bed load, the critical velocity can be determined as an average velocity in the hydrometric vertical assuming a definite velocity distribution and bed material characteristic.

During a flood with high culmination, bed erosion can reach a significantly greater volume. Intensity and high flow velocities significantly exceeded acceptable values for bed material for such floods. It caused damage to the bottom armoring and mass sediment motion. The mixing of materials of various grain sizes caused the washout of fine particles till the formation of a new amour (Bartnik 2006).

This paper presents the results of channel stability estimation at the Wkra River estuary. Estimation of the stability of the sandy bottom in the Wkra River was performed based on the average velocity criterion and bottom armouring.

\section{Hydrological characteristic of the Wkra River and data for analysis}

The Wkra River is a right bank inflow of the Narew River (Fig. 1), which is the end of the Middle Vistula section (Majewski 2013) according to the hydrographic division of Vistula basin.

The Wkra River has a typical lowland character with a small slope of the water table (average slope $0.5 \%$ ). The biggest inflows are the rivers: Raciążnica, Płonka and Sona, Mławka, Łydynia and Nasielna

The analysis was performed on the basis of the following input data:

- cross-section of Wkra channel and valley as a result of field levelling survey at km 1+000 (P-1, Fig. 2a) and km 3+200 (P-2, Fig. 3a);

- average bottom slope of the river equal to $0.09 \%$ from $\mathrm{km} 0+000$ to $\mathrm{km} 2+210$ (cross-section P-1) and $0.27 \%$ from $\mathrm{km} 2+210$ to $\mathrm{km} 5+440$ (cross-section $\mathrm{P}-2$ ) (MGGP S.A. 2003);

- characteristic discharges (MGGP S.A. 2003);

- samples of bottom materials taken from cross-sections P-1 and P-2 of the Wkra River.

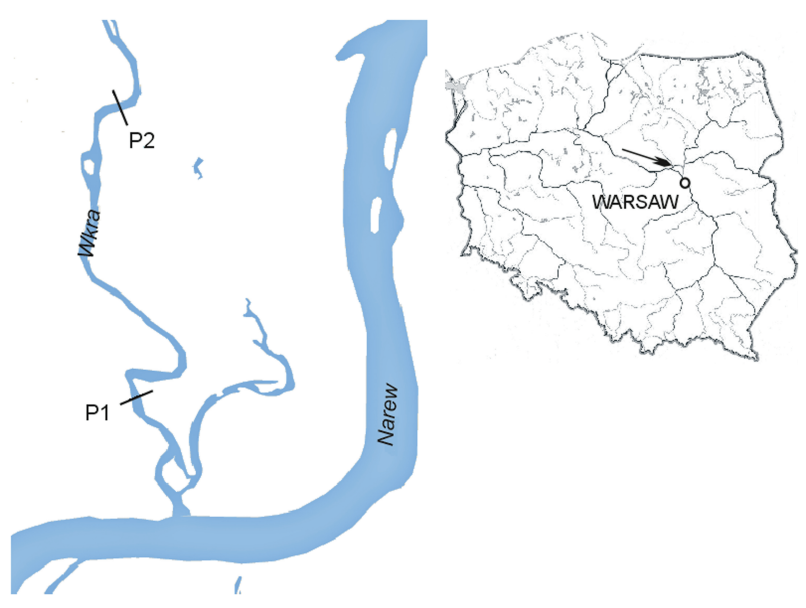

Fig. 1. Location of Wkra River estuary and studied cross-sections

Based on the available data for both cross-sections, the analysis of changeability of hydraulic parameters as a function of channel filling was performed. The results of this analysis were used for the determination of the capacity of channel, and also for establishing the rating curve (Fig. 2b and 3b). The roughness coefficient (Manning's n) after taking into account the features of the channel at studied river reaches was estimated as $n=0,040\left(\mathrm{~m}^{-1 / 3} \mathrm{~s}\right)$. This is recommended for large channels where the width of channel during high flow is greater than $30 \mathrm{~m}$ with a clean river bottom and vegetation along the banks (Ven Te Chow 1959; Dąbkowski et al. 1982).

Hydrological data were adopted from the Wkra River development plan (MGGP S.A. 2003). The characteristic discharges and design flows are presented in Table 1. The grain size characteristics of river bed material are presented in Table 2.

Table 1. Flow rate at a given probability in the sections P1 and P2 (MGGP S.A. 2003)

\begin{tabular}{|c|c|}
\hline The probability of flow & Flow rate at a given probability \\
\hline$[\%]$ & {$\left[\mathrm{m}^{3} / \mathrm{s}\right]$} \\
\hline 0,3 & 463 \\
\hline 0,5 & 427 \\
\hline 1 & 382 \\
\hline 2 & 336 \\
\hline 3 & 306 \\
\hline 5 & 273 \\
\hline 10 & 225 \\
\hline 50 & 102 \\
\hline
\end{tabular}

Table 2. The characteristics of Wkra River bed material in the analysed cross-section in [mm] (where $d_{x}$ is a particle diameter at the $X$ percentile)

\begin{tabular}{|c|c|c|c|c|c|c|c|}
\hline$d_{\%}$ & $d_{10}$ & $d_{16}$ & $d_{35}$ & $d_{50}$ & $d_{60}$ & $d_{84}$ & $d_{90}$ \\
\hline$[\mathrm{mm}]$ & 0,106 & 0,127 & 0,168 & 0,202 & 0,225 & 0,370 & 0,555 \\
\hline
\end{tabular}




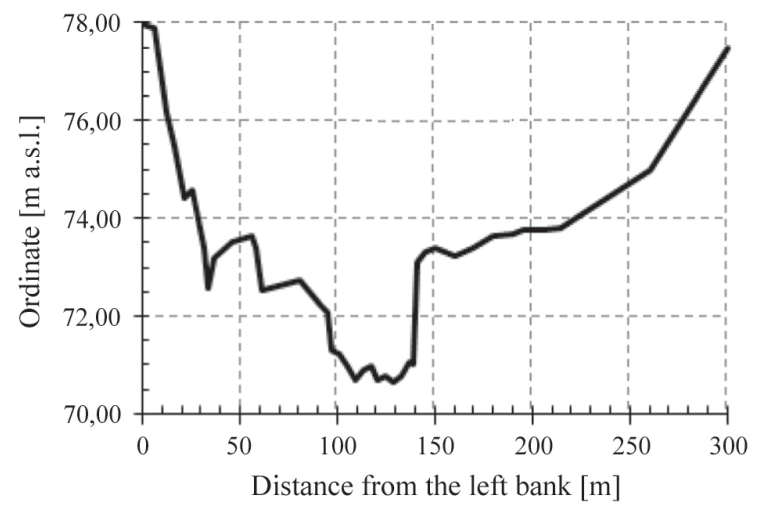

a)

Fig. 2. Cross-section of Wkra channel and valley (P-1) at km 1+000 (a) and rating curve at this point (b)

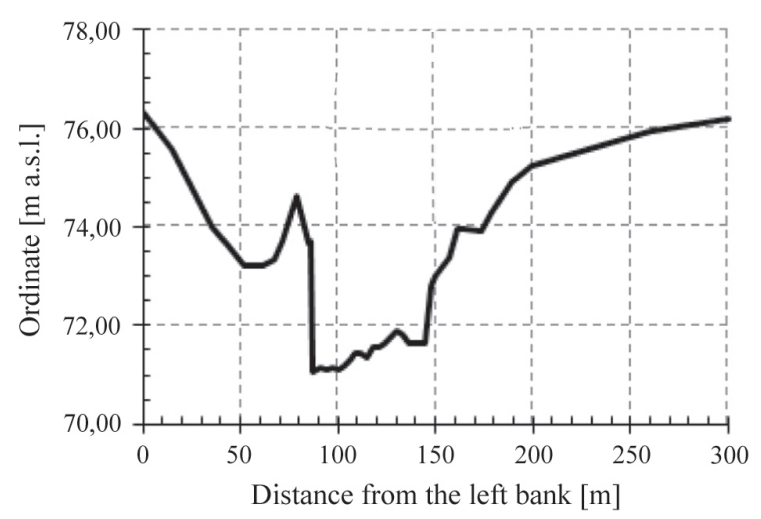

a)

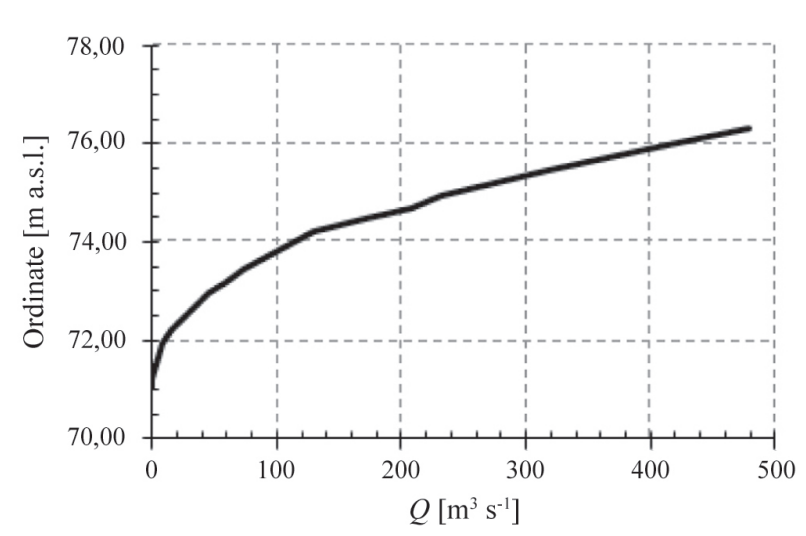

b)

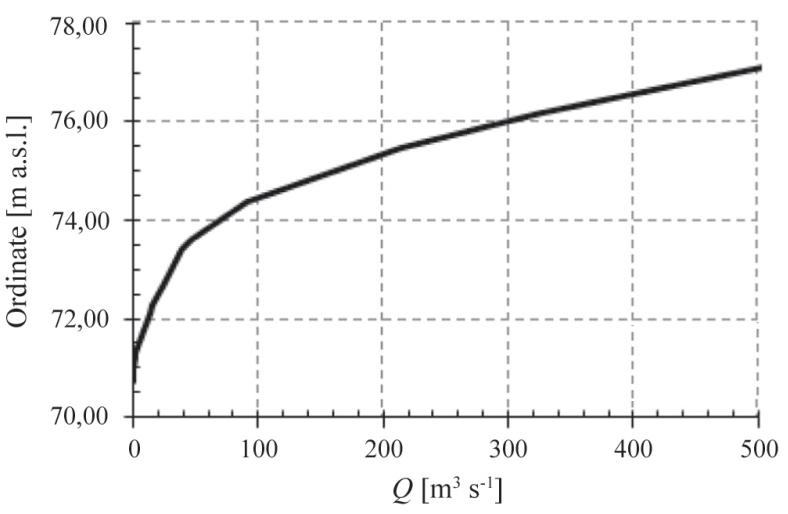

b)

Fig. 3. Cross-section of Wkra channel and valley (P-2) at km 3+200 (a) and rating curve at this point (b)

\section{Methodology of the estimation of channel stability}

For the assessment of river channel stability in the studied cross-section, the unit stream power $p_{s}$ was calculated according to equation (1) (Żelazo, Popek 2014). This is a parameter which describes the influence of a stream into a river bed.

$$
p_{s}=\frac{\rho g Q_{b} J}{B_{d}} ; \quad\left[\mathrm{Wm}^{2}\right]
$$

where: $\rho$ - water density $\left[\mathrm{kg} \mathrm{m}^{-3}\right] ; g$ - gravitational acceleration $\left[\mathrm{m} \mathrm{s}^{-2}\right] ; Q_{b}$ - bank discharge $\left[\mathrm{m}^{3} \mathrm{~s}^{-1}\right] ; J$ - bed channel slope [-]; $B_{d}-$ width of the channel bed [m].

Rivers with low $\left(p_{s} \leq 35 \mathrm{Wm}^{-2}\right)$ unit stream power have more stable channels. The morphological changes in such rivers are slow and are predominately visible after catastrophic floods. Rivers with high unit stream power $\left(p_{s}>\right.$ $35 \mathrm{Wm}^{-2}$ ) have unstable channels which are subjected continuous morphological changes (Żelazo, Popek 2014).

The second method for stability assessment applied in this study was the comparison of average velocity with initial sediment motion velocities and the intensity of this motion.

Using the formulas of Żelazo (1987), the following value was calculated:
- tear velocity $u_{0}$, the velocity which initiates sediment motion (equation 2);

- the initial velocity of sediment mass motion $u_{r}$; exceeding this value results in intense channel scouring and the instability of the channel (equation 3);

- the velocity of moderate sediment motion $u_{d}$ (acceptable velocity); this value corresponds to half of the intensity of bed load transport at $u_{r}$ velocity (equation 4).

$$
\begin{aligned}
& u_{0}=0,885 \sqrt{g d}\left(\frac{h}{d}\right)^{0,225} \\
& u_{r}=1,435 \sqrt{g d}\left(\frac{h}{d}\right)^{0,225} \\
& u_{d}=1,30 \sqrt{g d}\left(\frac{h}{d}\right)^{0,225}
\end{aligned}
$$

where: $d$ is average diameter of particle $[\mathrm{m}] ; h$ is a depth of the river $[\mathrm{m}] ; g-$ gravitational acceleration $\left[\mathrm{m} \mathrm{s}^{-2}\right]$.

The results of the calculation of velocities $u_{0}, u_{d}$ and $u_{r}$ were compared to average vertical velocities $u_{s}$ calculated with the Chezy-Manning equation. Additionally and supplementary to channel stability analysis, hydrodynamic stability analysis according to bed armouring criteria was applied. This type of channel stability balance was calculated based on shear stress increase during the 
bed armouring process. Bed amour is created by bottom particles which are not washed away by flow. The phenomenon of armour is a product of the gradual removal of fine particles. There are differences in this processing each case - it is different in natural river channels when compared to reservoirs and dams, where disturbances (for example weirs) cut off the sediment transport to the lower part of a river.

This is a long-lasting process and, due to the lack of alimentation of sediment, it ends when a state of equilibrium is reached again (armouring). This recovering of sediment balance also occurs for significant distances down dams. In such cases, the formation of the armour is accompanied by a lowering of the bed, with a change in the slope and the depth. Based on observation and measurement of the amour and the bottom, it is possible to conclude that it is a probabilistic phenomenon (Strużyński, Bartnik 2013).

The simulation of bed armour brakeage and beginning of sediment mass movement was performed according to the procedure of the prognosis of bed grain size changeability with the use of ARMOUR software (Bartnik 1992). The model is based on the findings of Gessler (1971), which states that the probability of the sustain of particular grains at the bottom of a channel is dependent on relative yield strength. According to Gessler (1971), it is a possible to determine grain size of the bed amour, based on the probability of the motionless of bed grains. The probability of the motionless of bed grains has been described by Gessler as a function of shear stress.

\section{Results and discussion}

Based on actual flow conditions (width of the channel $B_{d}$, average bed slope $J$, bank discharge $Q_{b}$ ) in the studies cross-section, the unit stream power $p_{s}$ was calculated. The value of bank discharge was identified based on the rating curves of particular cross-sections shown in Fig. 2 and 3. The results are presented in Table 3.

The calculated values of unit stream power with the range from 0.8 to $5.5 \mathrm{~W} \mathrm{~m}^{-2}$ indicate that at the studied reach the Wkra River channel is characterised by low stream power (below a threshold equal to $35 \mathrm{Wm}^{-2}$ ). This means that between cross-sections $\mathrm{P} 1$ and $\mathrm{P} 2$, the channel

Table 3. Results of the calculation of unit stream power $p_{s}$

\begin{tabular}{|c|c|c|c|c|}
\hline \multirow{2}{*}{$\begin{array}{c}\text { Cross-section } \\
{[\mathrm{km}]}\end{array}$} & \multicolumn{4}{|c|}{ Parameters } \\
\cline { 2 - 5 } & $\begin{array}{c}\text { Bed } \\
\text { width } \\
B_{d}[\mathrm{~m}]\end{array}$ & $\begin{array}{c}\text { Bank } \\
\text { discharge } \\
Q_{b}\left[\mathrm{~m}^{3} \mathrm{~s}^{-1}\right]\end{array}$ & $\begin{array}{c}\text { Average } \\
\text { bed slope } \\
J[-]\end{array}$ & $\begin{array}{c}\text { Stream } \\
\text { power } \\
p_{s}\left[\mathrm{~W} \mathrm{~m}^{-2}\right]\end{array}$ \\
\hline $1+000$ & 44,0 & 38,7 & 0,00009 & 0,8 \\
\hline $3+200$ & 57,0 & 118 & 0,00027 & 5,5 \\
\hline
\end{tabular}

should remain stable. The morphological changes in such a situation are predominately noticed after catastrophic floods (Żelazo, Popek 2014).

The second criterion of channel stability applied in this study is a comparison of average vertical velocities $u_{s}$ with velocities $u_{0}, u_{d}$ and $u_{r}$ The results of this comparison are shown in Fig. 4. For the calculation of characteristic velocities of sediment motion, the average diameter of particles $d_{50}=0,000202 \mathrm{~m}$ (Table 2) was used.

The results of the calculation for $\mathrm{P} 1$ cross-section indicate that at channel depth $h$ higher than $3,2 \mathrm{~m}$, the $u_{s}$ velocity exceeded the acceptable velocity $u_{d}$. The results of the calculation for $\mathrm{P} 2$ cross-section indicate that the $u_{s}$ velocity exceeded the $u_{r}$. Velocity at water depth in the channel equal to $2,40 \mathrm{~m}$. This suggests that in these conditions, the mass motion of bed load may occur and the threat of channel stability exists in this cross-section during floods.

The input data for the computation of amour breakage for the channel bottom was information about cross-sections shapes, preliminary grain sizes of bed material, the slope of the water surface and the computed Manning's $n$.

As a result of the increasing of shear stress in the river channel (increase of the water stage and flow) the phenomenon of particle sorting occurs. The fine particles are washed out and the coarser particles, which create bed armouring, remain in the river bed.

Further increasing of shear stress causes the breakage of the armouring. The condition of armour breakage is assumed when the probability of a sustain of $d_{84}$ diameter at the river bottom is less than $50 \%$ and the standard deviation for the calculated curve is equal to 1,3. After amour breakage, the material movement at the bottom is moderate until the probability of a sustain of $d_{84}$ diameter at the river bottom reaches zero. After this value, mass motion of bed material begins (the mixing and sorting of bed material declines).

The graphic presentation of this phenomenon is the grain size distributions shown in Fig. 5 and 6.

The results show that the armouring of the channel bed in both cross-sections is maintained only during low water depths. The armouring process occurs when, with increasing water depth, grain size distribution curves collocate below the initial curve. After the breakage of armouring, these curves begin to return to the initial curve and bed material is washed out and sorted. Until the beginning of the mass movement of bed material, the curves collocate under the initial curve and when the sorting processes decline, the bed material starts to be completely washed out and finally the curves return to initial conditions.

In this case, with increasing water depth in the channel up to about $40 \mathrm{~cm}$, the rupture of bed armour occurs. After 


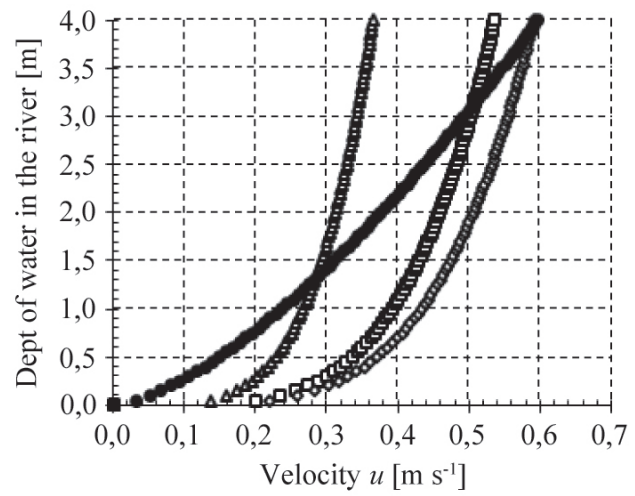

a) Cross-section P-1 (km 1+000)

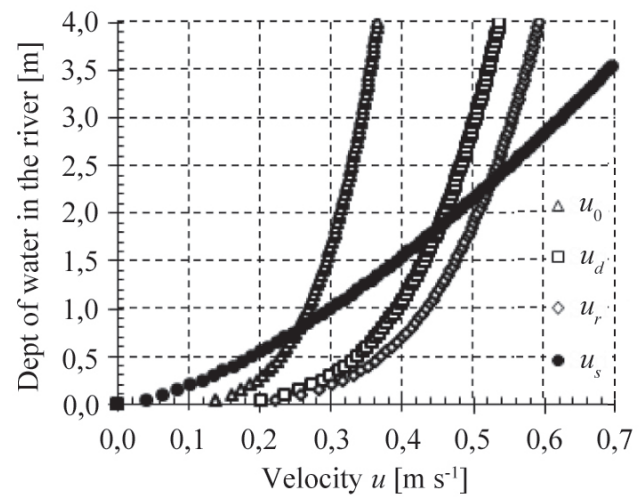

b) Cross-section P-2 (km 3+200)

Fig. 4. The changeability of $u_{s},\left(u_{0}\right),\left(u_{d}\right)$ and $\left(u_{r}\right)$ with depth at particular cross-sections

the exceedance of threshold depth, which in P1 is 4,39 m and in $\mathrm{P} 2$ is $1,75 \mathrm{~m}$, the mass motion of bed load begins. This also means that mass motion in P-2 cross-section appear at discharges lower than $Q_{50 \%}$, and in P-1 cross-section at discharges higher than $Q_{0.3 \%}$.

The conducted analysis shows that at the river reach represented by P- 2 cross-section, linear erosion can occur during relatively low flow (more frequent than a two-year flood).

The estuary reach represented by $\mathrm{P}-1$ cross-section is characterised by increased stability in comparison to the upstream reach, however, the rupture of armour can happened even at low water depth.

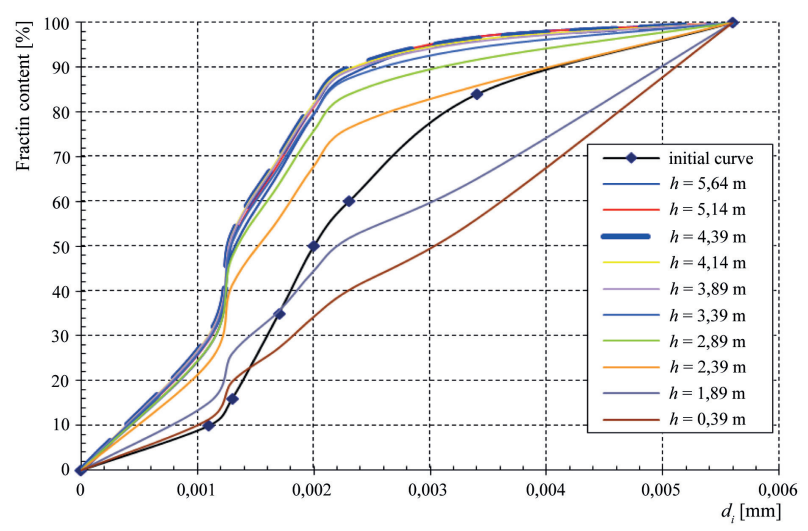

Fig. 5. Prognosis of bed particle grain size curves in the cross-section P-1 for different depths of water

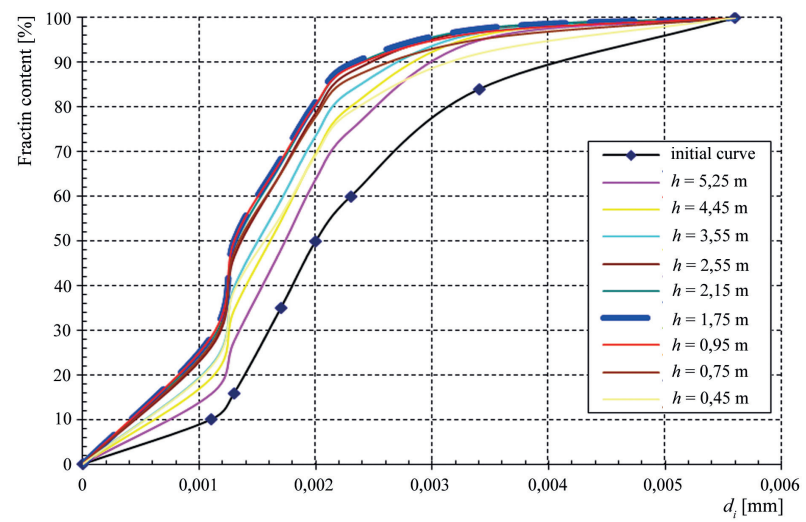

Fig. 6. Prognosis of bed particle grain size curves in the cross-section P-2 for different water depths

\section{Summary}

Considering the current flow conditions and morphological characteristics of the channel at the studied River Wkra reach, it is hard to estimate the channel stability clearly. The calculated unit stream power $\left(p_{s}=3,4-\right.$ $\left.4,0 \mathrm{~W} \mathrm{~m}^{-2}\right)$ conforms to stable channels with $\left(p_{s} \leq 35 \mathrm{~W} \mathrm{~m}^{-2}\right)$. However, the analysed velocities which characterised the beginning of the sediment motion and its intensity indicate threats of channel stability, especially in cases of longterm persistent of high water stages.

The prediction of channel bed stability loss was computed with the use of ARMOUR software. The results indicate that the breakage of bed amour happens at both considered cross-sections at a relatively low channel depth $-40 \mathrm{~cm}$. The sediment mass motion at P-2 cross-section begins at a flow slightly lower than $Q_{50 \%}$, and at P-1 crosssection at a flow higher than $Q_{0,3 \%}$.

Bibliography

Bajkiewicz-Grabowska E., Mikulski Z., 2007, General Hydrology, (in Polish), PWN, Warszawa, 338 pp.

Bartnik W., 1992, Fluvial hydraulics of streams and mountain rivers with a movable bed. Beginning of bedload transport, (in Polish), Zeszyty Naukowe AR w Krakowie, Seria Inżynieria Środowiska, $171 \mathrm{pp}$.

Bartnik W., 2006, Hydromorphological characterisations of rivers and streams, (in Polish), Infrastructure and Ecology of Rural Areas, 4 (1), 143-174

Bartnik W., Majewski W., Łapuszek M., Ratomski J., 2007, The estimation of hydrodynamic balance of the lower Dunajec below the hydro-energy power plant, (in Polish), Infrastructure and Ecology of Rural Areas, 4 (1), 21-37

Bąk Ł., Michalik A., 2010, Processes of erosion and aggradation within the regulated section of the Czarna Nida River, (in Polish), Infrastructure and Ecology of Rural Areas, 8 (1), 179-189 
Bednarczyk S., Duszyński R., 2008, The hydraulic and hydrotechnical basis of regulation and the revitalisation of rivers, (in Polish), Wydawnictwo Politechniki Gdańskiej, Gdańsk, $224 \mathrm{pp}$.

Dąbkowski L., Skibiński J., Żbikowski A., 1982, The hydraulic basis of land reclamation projects, (in Polish), Państwowe Wydawnictwo Rolnicze i Leśne, Warszawa, 534 pp.

Gessler J., 1971, Beginning and ceasing of sediment motion, [in:] River Mechanics, H.W. Shen (ed.), Water Resources Publications, Littleton, Colorado, USA

Hämmerling M., Zawadzki P., Walczak N., Wierzbicki M., 2014a, Bed load transport in rivers. Part I: start moving, shear stress, (in Polish), Acta Scientorum Polonorum. Formatio Circumiectus, 13 (4), 109-120

Hämmerling M., Zawadzki P., Walczak N., Wierzbicki M., 2014b, Bed load transport in rivers. Part II: boundary velocity and traction intensity, (in Polish), Acta Scientiarum Polonorum. Formatio Circumiectus, 13 (4), 121-131

Kaszowski L., Kotarba A., 1970, Effect of catastrophic floods on the course of fluvial processes, (in Polish), Prace Geograficzne IG PAN, 80, 5-87

Majewski W., 2013, Sustainable development of the Lower Vistula, Meteorolology Hydrology and Water Management, 1 (1), 33-38

MGGP S.A., 2003, Study on areas with no dikes, endangered by floods, (in Polish), RZGW, Warszawa, 140 pp.

Odgaard A.J., 1984, Flow and bed topography in an alluvial channel bend, Journal of Hydraulic Engineering, 110 (4), 521-536, DOI: 10.1061/(ASCE)0733-9429(1984)110:4(521)

Popek Z., 2004, Determination of critical velocities for finegrained bed material in a laboratory flume with a flat bottom, (in Polish), Scientific Review Engineering and Environmental Sciences, 2 (29), 21-31

Popek Z., 2010, Characteristic of sandy bedload in the small lowland river, (in Polish), Acta Scientiarum Polonorum. Formatio Circumiectus, 9 (3), 45-54

Przedwojski B., 1998, The morphology of rivers and forecasting of river processes, (in Polish), Wydawnictwa Akademii Rolniczej im. Augusta Cieszkowskiego w Poznaniu, Poznań, $292 \mathrm{pp}$.

Siwicki P., Urbański J., 2004, Local scour below water structures and their influence on environment, (in Polish), Acta Scientiarum Polonorum Architectura, 3 (2), 113-120

Siwicki P., Urbański J., 2007, Investigation of local scour on weir model with changing length of bed protection in downstream, (in Polish), [in:] Proceedings of XII Dam Monitoring International Conference, Stare Jabłonki, 19-22 June, 325-336

Strużyński A., Bartnik W., Kulesza K., Czoch K., 2013, Hydrodynamic balance as important parameter influencing the ecological status of Carpathian rivers, (in Polish), Annual Set The Environment Protection, 15, 2591-2610

Urbański J., Hejduk L., 2014, Analysis of sizes of local scour as a result of flood, (in Polish), [in:] Monografie Komitetu Gospodarki Wodnej PAN. II Krajowy Kongres Hydrologiczny. Tom I: Hydrologia w inżynierii i gospodarce wodnej, K. Banasik, L. Hejduk, E. Kaznowska (eds.), Warszawa, 389-400

Ven Te Chow, 1959, Open-channel hydraulics, McGraw-Hill, New York, USA, 680 pp.

Żelazo J., 1987, Critical velocities for non-cohesive grounds, Annals of Warsaw Agricultural University, 23, 65-70

Żelazo J., Popek Z., 2014, The basis of river restoration, (in Polish), Wydawnictwo SGGW, Warszawa, 308 pp. 